Economia e Sociedade, Campinas, Unicamp. IE.

http://dx.doi.org/10.1590/1982-3533.2017v26n3art2

\title{
O marxismo e outras influências sobre o pensamento de Ignacio Rangel *
}

\author{
Elias Jabbour **
}

\begin{abstract}
Resumo
Tendo em vista os debates iniciados sobre a obra de Ignacio de Mourão Rangel, no bojo de seu centenário de nascimento (2014), este artigo tem por objetivo uma discussão inicial sobre as influências intelectuais exercidas sobre o citado autor ao longo de sua extensa obra, com destaque ao marxismo. Advogamos que a originalidade do pensamento de Rangel foi resultante de diversas influências desde filosóficas (Hegel e Kant) -, passando por Adam Smith e, principalmente, Karl Marx, Vladimir Lênin - até a absorção, via Schumpeter, das ondas largas da conjuntura de Kondratiev e a utilização dos postulados keynesianos. Tratamse de influências que explicam, em grande monta, o êxito - em Rangel - tanto da transformação do materialismo histórico em algo profundamente brasileiro quanto a elaboração de uma Economia Política do Brasil.
\end{abstract}

Palavras-chave: Pensamento de Ignacio Rangel; Influências intelectuais; Materialismo histórico; Desenvolvimento; Brasil.

\begin{abstract}
Marxism and other influences on Ignacio Rangel's line of thought

In view of the discussions started regarding the work of Ignacio de Mourão Rangel, in the midst of his birth centenary (2014), this article aims to discuss Rangel's influences throughout his extensive work. We argue that Rangel Marxist thought - the cause and consequence of his broad view of science and the evolutionary nature of the economy - was the result of several influences: from philosophers such as Hegel and Kant to Adam Smith and, mainly, Karl Marx and Vladimir Lenin. He absorbed, through the work of Schumpeter, the concept of Kondratiev long-term cycles. Rangel also used Keynesian postulates. These influences largely explain Rangel's success in turning historical materialism into something deeply Brazilian and in developing a Brazilian Political Economy.
\end{abstract}

KEYWORDS: Ignacio Rangel's thought; Intellectual influences; Historical materialism; Development; Brazil.

JEL B24; B51.

\footnotetext{
*Artigo recebido em 6 de junho de 2015 e aprovado em 9 de fevereiro de 2017.

** Professor Adjunto da Faculdade de Ciências Econômicas e do Programa de Pós-Graduação em Ciências Econômicas da Universidade do Estado do Rio de Janeiro (PPGCE-FCE-UERJ). Email: eliasjabbour@terra.com.br.
}

Economia e Sociedade, Campinas, v. 26, n. 3 (61), p. 561-583, dez. 2017. 
Como internacionalista - sem prejuízo do meu patriotismo brasileiro - sinto-me solidário com o socialismo, à medida que este é o grande propugnador da paz. E quero que o capitalismo brasileiro (...) seja próspero, porque isso o interessará na paz. Ou é mesmo verdade, segundo a tradição leninista, que a luta pela paz é o caminho forçoso do socialismo, ou este não me interessa, porque, fora da paz, não há futuro, nem socialista, nem qualquer outro. $O$ futuro é, afinal, tempo do homem. E os netos que continuam a chegar, assim como os bisnetos que não devem tardar, exigem que a nação onde eles deverão viver seja uma nação próspera. Não uma nação utópica, postergada para futuro imprevisível, mas uma nação concreta, que é o desdobramento da nossa (Ignacio Rangel)

\section{Introdução}

Impossível não lembrar os efeitos da Revolução de 1930 sobre o país sem citar a explosão de criatividade artística e intelectual que se seguiu a este acontecimento. Pode se dizer que na esteira deste processo surge o que convencionou chamar de "pensamento social brasileiro", cuja característica principal é a formação de uma plêiade de pensadores cujo brilhantismo e capacidade criativa apenas expressavam o clima de otimismo que passou a reger o Brasil em substituição ao pessimismo inerente aos círculos intelectuais pré-1930. Produtos de uma época, Gilberto Freyre, Caio Prado Jr., Sergio Buarque de Holanda e Celso Furtado talvez os nomes mais conhecidos do grande público e verdadeiros símbolos do pensamento nacional pós-1930. Nesta plêiade de grandes pensadores brasileiros merece, não menor, destaque o economista maranhense Ignacio Rangel.

Curiosamente, e paradoxal, apesar de ser reconhecido como "provavelmente o mais original analista do desenvolvimento econômico brasileiro" (Bresser Pereira e Rego, 1993, p. 98), Ignacio Rangel ainda é pouco lido e discutido pelo grande público interessado em temas brasileiros, incluindo os economistas ${ }^{1}$. Poderíamos tecer vários comentários explicativos a este paradoxo. Por exemplo, sua independência intelectual resultou em grandes diferenças com relação a todas as correntes de opinião dominantes da época. Rangel era um marxista, ao mesmo tempo crítico tanto

(1) Caberia inteiramente a Rangel esta descrição de Robinson (1942) sobre a (não) aceitação de Marx na academia: Until recently, Marx used in academy circles with contemptuous silence, broken only by an ocasional mocking footnote. 
do "marxismo oficial" quanto da escola dependentista, dominante na esquerda acadêmica desde a década de 1960 até os nossos dias. Como economista, ousou demonstrar os limites teóricos e conceituais das duas grandes correntes do pensamento econômico, o estruturalismo e o monetarismo.

Polemista, nunca aceitou a tese dominante, pela esquerda, da reforma agrária como pressuposto ao processo de industrialização. Nem tampouco acatou noções que colocavam a razão dos problemas do desenvolvimento industrial brasileiro numa agricultura que combinava "baixa produtividade" e "oferta inelástica". Sem nenhuma amarra ideológica - e numa época de radicalização de posições acerca das privatizações - o mesmo homem que teve participação ativa nos projetos que deram origem a empresas estatais como a Petrobrás e a Eletrobrás vaticinou a necessidade de reformas institucionais que viabilizassem uma completa reorganização de atividades entre Estado e iniciativa privada ${ }^{2}$.

Não são poucos os fatores e circunstâncias que levaram a obra e o gênio de Ignacio Rangel a um alto grau de ostracismo. Impossível separar o fenômeno da conjuntura que o cria: o ostracismo de suas ideias tem razão também - nos ventos ultraliberais que chegaram ao país e submeterem o Estado Nacional a um processo de desmonte das instituições criadas ao longo do período desenvolvimentista. Por outro lado, seu centenário de

(2) Sobre esta reorganização de atividades, indicamos a leitura do posfácio à quinta edição de “A Inflação Brasileira” (1978). Acerca deste posfácio, expressa-se Bresser Pereira (2005) conforme se lê: Em 1978, com sua concordância, propus a meu amigo e editor, Caio Graco Prado, da Editora Brasiliense, que publicasse uma nova edição de A Inflação Brasileira. Dessa forma queria fazer lembrar o grande economista, que ainda não se recuperara de seu afastamento do BNDES e da vida pública brasileira. A nova edição esgotou-se rapidamente, não apenas porque o livro original que foi publicado sem alterações, era extraordinário, mas porque Rangel incluiu nele um "Pósfacio" antológico. Nele, ao invés de voltar às suas ideias dos anos 60, avançou, mostrando de forma pioneira que a economia brasileira estava caminhando na direção de uma grande crise de financiamento, na medida que o Estado brasileiro estava perdendo capacidade para realizar a tarefa fundamental que lhe coubera desde os tempos de Vargas: financiar os investimentos - especialmente dos investimentos na infraestrutura e nos serviços públicos. Estava ali a previsão da grande crise dos anos 80, e um esboço da teoria da crise fiscal do Estado, que, durante os anos 80 , eu procuraria desenvolver em vários trabalhos. Estava ali também a proposta de como resolver a questão, através de um novo tipo de financiamento, baseado na hipoteca das receitas dos serviços públicos. 
nascimento (2014) tornou-se um motivo para debates de fundo envolvendo não somente suas ideias per se, mas também a assuntos relacionados ao desenvolvimento socioeconômico do Brasil.

Neste sentido, este artigo inicial tem por objetivo buscar as principais influências intelectuais exercidas sobre Ignacio Rangel, com destaque ao marxismo e sua extensão na obra econômica de Lênin. Para tanto, o artigo está dividido em três seções, a contar esta pequena nota introdutória. Na seção 1 buscamos inicialmente elencar as influências filosóficas exercidas desde seu pai até Hegel e Kant. Em seguida, passamos a abordar a influência de Adam Smith, Karl Marx e Vladimir Lênin. Na economia não marxista é fundamental demonstrar as influências exercidas J. M. Keynes e a objetividade intrínseca na relação entre ciclos econômicos, investimento e progresso técnico inerente à obra de J. Schumpeter. Na segunda seção, a título de conclusão, alguns comentários serão tecidos acerca da importância da obra do autor.

\section{As influências}

A sofisticação, o senso crítico e completa independência intelectual são resultado, em Rangel, da combinação entre abstração e dialética que muito cedo chegou a si pelas palavras de seu próprio pai, José Lucas Mourão Rangel -, juiz de direito, crítico à República Velha e simpatizante da Coluna Prestes -, sua primeira grande influência intelectual, sob a forma do ensino da ciência das leis de forma peculiar a um menino. Menino este que, no futuro, seguindo os passos do pai e do avô se formaria em direito. Seu caminho de combate o tornaria, ainda com 16 anos de idade, parte - com armas em punho - da Revolução de 1930 e da Intentona Comunista de $1935^{3}$.

\subsection{Historicidade das leis da ciência e o duplo processo evolutivo da ciência econômica}

Em combinação à sua iniciação científica no seio da própria família e da lógica dialética intrínseca à Filosofia do Direito, a filosofia clássica

(3) Sobre a vida e obra de Rangel, indicamos Mamigonian (1987, 1997 e 2005), Bresser Pereira e Rego (1993), Corrêa; Palhano; Costa e Braga (1991) e Castro, Bielshowsky e Benjamin (2014). 
alemã é o assento por onde, não somente suas ideias, mas - também, e principalmente - sua própria visão de ciência econômica ganharam contornos originais. Hegel e Kant transparecem nos enunciados rangelianos sob forma de filosofia aplicada ao método da Economia Política. A visão marxiana de correlação múltiplas dos fenômenos, ocultas à observação micro já estava presente em Hegel e na sua compreensão totalizante e sociológicas das ideias.

A própria dualidade básica, categoria rangeliana basilar, é um exercício de abstração inspirada em $\mathrm{Hegel}^{4}$. Da própria abstração hegeliana vem a transformação do Estado - não somente como ente político - em categoria analítica e historicizada por Marx e Engels. A ideia hegeliana de um Estado forte é muito explorada por Rangel em toda sua obra. Particularidade rangeliana, neste tocante, é a não redução do Estado a um mero balcão de negócios das classes dominantes e sim uma instituição sob intensa pressão "de baixo" e "de cima", por onde-se processam as transformações institucionais necessárias a abertura de horizontes e mesmo, do caminho peculiar e brasileiro ao socialismo.

Kant pode ser observado, em Rangel, como uma outra combinação original. O que o autor sintetiza como historicidade das leis da ciência é encerrado numa visão da ciência econômica como matéria histórica, consequentemente, sensível a um duplo processo evolutivo. Em suas palavras (Rangel, [1956] 2005, p. 204):

A economia é uma ciência histórica por excelência - qualidade que partilha das outras ciências sociais. Quer isso dizer que está submetida a um duplo processo evolutivo: o fenomenal e o nomenal. E quer dizer também que, ao contrário das ciências da natureza, especialmente as da natureza não viva, não pode ser estudada senão nesse duplo contexto.

(4) Segundo Mercadante (1997, p. 47): Mas a dualidade básica é resultado sobretudo de um admirável processo de abstração, inspirado em Hegel. Neste pensador deram-se a supervalorização da abstração e uma desvalorização do abstrato. Para ele, abstrair era superar e reduzir a matéria sensível, que é simples fenômeno, ao essencial, que só se manifesta no conceito. 
Tendo como pressuposto o caráter histórico e, consequentemente, o duplo caráter evolutivo da ciência econômica, os limites de fronteira com os desígnios da "economia vulgar", tornam-se mais claros. Para Rangel ([1956] 2005, p. 204-205):

O conceito vulgar admite explicitamente apenas a evolução fenomenal da economia. Cada nova teoria surge como resultado de uma representação mais precisa da realidade transcendente, a qual, explicitamente, permaneceria sempre igual a si mesma. Assim a análise smithiana seria, em comparação com a fisiocrática, apenas uma representação mais perfeita, que considera certas facetas que Quesnay e seus amigos uniria a análise neoclássica à clássica, a keynesiana à neoclássica.

Em contraponto à perspectiva "vulgar", vaticina Rangel ([1956] 2005, p. 205):

Se admitirmos que a economia, além dessa evolução "fenomenal" (como representação, como ideia da coisa, como 'coisa para nós', no sentido kantiano), é também susceptível de outra evolução (a evolução "nominal" como objeto, coisa representada, 'coisa em si') seremos levados a uma atitude mais respeitosa para com o que os antigos pensaram. Esse pensamento seria talvez prejudicado pelas claudicâncias do método, pelo instrumental imperfeito de análise, mas continha uma espécie de verdade que não passou às teorias mais recentes pelo simples fato de que refletia uma realidade que deixou de existir, que se transformou, por seu próprio impulso interno noutra realidade.

Talvez seja essa postura para com as ditas "fronteiras de conhecimento" e sua relação com a evolução da ciência econômica é que Rangel, muitas vezes de forma carinhosa, outras de forma pejorativa, é visto como um "heterodoxo eclético". O respeito aos clássicos é um imperioso de seu comportamento e expressão de sua amplitude e tolerância típicas dos valores nascidos da filosofia clássica grega de Platão, Sócrates, Aristóteles e Heródoto que ganha grande expressão em $O$ Fausto, de Goethe ${ }^{5}$. Essa objetividade histórica levou Rangel a perceber que o pressuposto da

(5) Neste aspecto, segundo Mamigonian (1997) cabiam a Rangel as palavras de Goethe sobre o papel das influências intelectuais: somente quando transformamos as riquezas dos outros em nossas próprias riquezas seremos, de fato, capazes de dar vida a algo de grandioso. 
utilidade marginal do capital não deve ser ideológico e sim apresentado em seu aspecto abstrato em conformidade com seu lugar na história. Da mesma forma, é que o planejamento econômico, influenciado pela visão hegeliana de Estado, e os resultados apresentados pela vitória da URSS na Segunda Guerra Mundial, torna-se principal componente comprovante de validação científica da ciência econômica.

\subsection{Adam Smith e Marx: a economia política da nação}

Sobre a influência smithiana na obra de Rangel, duas considerações. A primeira referente ao próprio título de seu clássico, A Riqueza das Nações. O tempo histórico da escrita do livro nos permite contextualiza-lo nos marcos da transição feudalismo-capitalismo e da consolidação da própria nação como ente histórico, consolidada - sobretudo entre as três últimas décadas do século XVIII até as unificações ocorridas a partir de 1840 na Europa. Esta referida transição, que ocorre nos marcos da Iluminismo, lança luzes à própria metamorfose no âmbito da Economia Política onde a troca de mercadorias expressa uma "ordem natural" em detrimento da ordem natural fisiocrática "revelada".

Ora, se temos como um dos objetos da Economia Política a compreensão das leis que regem o processo de desenvolvimento em uma economia de mercado, porém sob regulação do Estado, fica óbvia a relação entre a obra de Smith, a moderna Economia Política e a importância, sem nenhuma relatividade, da nação - e no caso brasileiro, em Rangel, na centralidade da Questão Nacional (imperialismo x socialismo/projetos nacionais autônomos).

A segunda questão refere-se, necessariamente, na concepção - no bojo das unificações políticas europeias e sua correspondência na unificação, também, de mercados nacionais ${ }^{7}$ - da categoria smithiana de divisão social do trabalho como expressão de dois processos simultâneos: 1) a expansão da economia de mercado como expressão máxima do

(6) Sobre esta metamorfose na Economia Política, sugerimos a leitura de Belluzzo (1998)

(7) Ao caso brasileiro tal correspondência ocorre no bojo da Revolução de 1930 encetando mudanças institucionais que viabilizaram o início do processo industrial de substituição de importações e a unificação do mercado nacional, quebrando a lógica de hinterland expressada no papel gravitacional das cidades portuárias (porto-empório). 
processo de desenvolvimento e da diferenciação social e 2) O progresso técnico como uma das leitmotivs indutoras da expansão da economia de mercado e, consequentemente, da divisão social do trabalho. Todo esse enunciado está, de forma ampla e criativa, presente em Ignacio Rangel.

Sobre Karl Marx, de antemão, duas questões seguidas de algumas observações. Como enquadrar o sistema teórico fundado em Ignacio Rangel? É possível classificar o autor dentro de uma rigidez teóricometodológica limitada pelas circunstâncias da história e do modo de produção complexo em desenvolvimento no Brasil dos anos de 1930 a 1960? Às duas questões, a resposta é sim. Ignacio Rangel foi um marxista de alta consequência na proporção da clareza que tinha sobre as leis econômicas e sua não universalidade, daí seu êxito na busca de uma visão de conjunto do processo de acumulação no Brasil, adaptando o materialismo histórico às peculiaridades de uma formação social complexa, como a brasileira. Engels (1990, p. 127) resume este aspecto fundamental ao método da Economia Política, como segue:

As condições sob as quais os homens produzem e trocam o que foi produzido variam muito para cada país e, dentro de cada país, de geração para geração. Por isso, a Economia Política não pode ser a mesma para todos os países nem para todas as épocas históricas.

O realismo, sob forma de abstração, é intrínseco na análise de elementos vivos; abstração esta permitiu também a Rangel, à moda marxiana, a percepção de relações gerais abstratas, entre elas divisão social do trabalho, dinheiro e valor até a observação e percepção de complexos sistemas econômicos, que ao elevarem-se do simples, permite maior totalidade na análise da categoria valor seguindo até o valor de troca para o Estado, à troca internacional e para o mercado mundial. Neste sentido, sua maior proeza intelectual, que o distingue diante de outros marxistas brasileiros e latinoamericanos, está na transformação do marxismo em algo

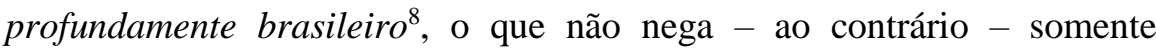

(8) Tal postura diante da ciência, não somente como instrumento de análise, mas principalmente de transformação revolucionária da sociedade dá pleno sentido à seguinte afirmação de Bielshowski (1996, p. 210), onde se lê: A obra de Ignacio Rangel corresponde a um original ensaio de adaptação do materialismo histórico e da teoria econômica à análise do caso brasileiro, que o autor empreendeu com sentido da busca sistemática da especificidade das leis da formação de formação histórica e de funcionamento da economia brasileira. 
amplifica a própria universalidade do materialismo histórico cuja validação teórica só se demonstra no "pouso no concreto": na análise de determinada formação social ${ }^{9}$.

Rangel observava o capital e sua reprodução como um fenômeno cíclico, em perfeita conformidade com a lógica dialética tendo o desequilíbrio como pressuposto, mediado pelo planejamento, do desenvolvimento. Nenhuma oferta produz sua própria demanda, conforme a "lei de Say". As crises existem, pois é, por demais improvável a manutenção de um "equilíbrio subjetivo" entre produtor e comprador.

Em Rangel, esta lógica de círculos, virtuosos e viciosos, no concreto, incidem diretamente sobre nosso país, ao ter nessa manifestação periódica germes de transformações no seio da hegemonia do capitalismo central e entre as formas históricas do capital, conforme a evolução sistêmica do capitalismo comercial, ao industrial daí o financeiro e a sua anomalia financeirizada, num caminho de consolidação do divórcio entre valor de troca e valor de uso. Marx e Engels foram a trilha objetiva que levou Rangel a Kondratiev, de forma que o materialismo histórico e a sistematização dos ciclos longos da conjuntura (Kondratiev) ${ }^{10}$ se combinassem no longo

(9) Marx utilizou de forma muito genérica a categoria de formação social como se vê no Prefácio à Crítica da Economia Política onde emprega esta expressão no mesmo sentido que deu à categoria de sociedade. A expressão e/ou categoria de formação social ganha força na análise estruturalista, porém ainda muito pobre, pois a relaciona sem muito rigor à categoria de modo de produção e que em muitos casos, como frequentemente pode se observar em Althusser, acaba negando a unidade dialética de continuidade e descontinuidade do tempo histórico. Em oposição à leitura estruturalista, Emilio Sereni aponta que a noção de formação social permite revelar o funcionamento lógico-estrutural e/ou sociológico de uma dada sociedade. Assim, em Sereni, a categoria de formação social ganha mais corpo e mais legitimidade epistemológica. Porém, numa visão particular, é em Milton Santos que essa categoria atinge sua maturidade e ápice como unidade científica, pois para ele, mesmo que a formação social seja intrinsecamente ligada à categoria de modo de produção, ela está ligada à evolução de uma dada sociedade em sua totalidade histórica. De nosso turno, acreditamos que a categoria de formação social é a fronteira última, e mais sofisticada, das ciências sociais. Sobre esta categoria, sugerimos: Sereni (1975), Santos (1982) e Mamigonian (1996).

(10) Sobre os ciclos de Kondratiev, sugerimos a leitura de: Kondratiev (1992); Korotayev, Andrey e Tsirel (2010); Schumpeter (1939), em especial o capítulo VI "Time series and their normal"; Martins (2009). Rostov (1975); Salomon (1987). 
caminho rangeliano de adaptação do materialismo histórico às condições brasileiras.

A combinação entre os dois clássicos do materialismo histórico, o princípio da não universalidade das leis econômicas e os ciclos longos da conjuntura gera uma referência muito particular de análise: a tese da dualidade básica da economia e formação social brasileiras. Segundo Rangel (1957 [2005], p. 295), "a dualidade é a lei fundamental da economia brasileira". Uma nova forma de abordar as categorias marxistas tais como "forças produtivas" e "relações de produção" é inaugurada por Rangel em uma dialética onde a teoria dos ciclos longos é absorvida de forma a perceber seus impulsos sob o próprio processo de desenvolvimento das forças produtivas do país ${ }^{11}$.

O nosso modo de produção, diferentemente do percebido nos países centrais, teria uma dupla natureza, tratar-se-ia de uma dualidade, um modo de produção complexo. Este caráter dual do modo de produção com impactos sobre toda as instituições e à própria sociedade. Segundo Rangel (1957 [2005]):

A dualidade é a lei fundamental da economia brasileira. Podemos formula-la nos seguintes termos: a economia brasileira se rege basicamente, em todos os níveis, por duas ordens de leis tendenciais, que imperam respectivamente no campo das relações internas de produção e no das relações externas de produção. Essas duas formações econômicas básicas (...) não se limitam a coexistir. Pressionam continuamente uma sobre a outro, estão em permanente conflito. (...)

Sob a perspectiva do Brasil, e seu processo de desenvolvimento, como uma formação que se movimenta sob "duas ordens de leis tendências" que operam em unidade de contrários, é imperativo afirmar a dualidade básica da economia e formação brasileiras como a própria lei do processo de desenvolvimento do nosso país. O que significa que a obra de Rangel não deve ser tomada no particular, por exemplo, em análises isoladas da inflação, questão agrária etc. Toda o pensamento do autor é marcado pela

(11) Sobre a dualidade brasileira ler Rangel (1957 [2005]) (1981[2005]). 
dualidade como o geral, o fio de condutor que perpassa todas as grandes questões desenvolvidas.

\subsection{Lênin: dinâmica cidade-campo, imperialismo e desenvolvimento desigual}

A nosso ver, a influência de Lênin é significativa, não se tratando de algo menor na construção de seu pensamento, convicções e elaborações. Pode-se dizer que o grau de desconhecimento desta influência é inversamente proporcional à sua importância para Rangel. Interessante notar que o marxismo desenvolvido por Lênin - amplamente apropriado por Rangel - ter sido a fonte intelectual que serviu de base às discordâncias com seus contemporâneos marxistas e estruturalistas. Indo além, podemos indicar uma linha entre a dificuldade de interpretação e assimilação do pensamento de Rangel com o grande desconhecimento da, vasta e profunda, obra econômica de Lênin ${ }^{12}$.

A raiz das discordâncias entre Rangel, os marxistas dependentistas e estruturalistas está na percepção - muito comum entre ambas escolas de pensamento - de uma dinâmica industrial dependente do desempenho da agricultura. Em outras palavras: o não-desenvolvimento de nossa agricultura era fator de retardamento ao desenvolvimento nacional como um todo $^{13}$. Segundo Leite (2014, p. 168):

O consenso "pessimista" quanto ao futuro da economia brasileira, pode ser sintetizado na seguinte maneira: em razão da ausência de

(12) Elaborações interessantes de Lênin sobre a relação entre campo, cidade e o processo de industrialização podem ser vistas em Lênin ([1893] 1972); ([1893] 1963) e ([1915] 1917). A Lênin ainda cabe um desenvolvimento das teses de Ricardo e Marx sobre as rendas diferencial e absoluta da terra, com ênfase na demonstração das formas como a renda absoluta pode travar o desenvolvimento técnico da agricultura e demonstrando a inconsequência de determinados enunciados vulgares param quem sobre uma suposta existência da "lei da fertilidade decrescente do solo". Em Rangel ([1978] 2005), essa influência leniniana sobre as "rendas da terra" é perceptível na elaboração, por Rangel, da chamada 4" renda da terra ("a terra como parâmetro financeiro"), com grande serventia à explicação do preço da terra no Brasil em tempos de adicção por Preferência pela Liquidez.

(13) Bom assinalar que esta opinião sobre a relação entre campo x cidade e agricultura $\mathrm{x}$ indústria tratava-se de um amplo consenso de autores que variavam de Celso Furtado (estruturalista) até Caio Prado (marxista). 
uma revolução/modernização do campo, a agricultura crescia extensivamente, constituindo-se num setor que não respondia aos preços, tinha uma oferta inelástica, retardava o desenvolvimento da indústria (Grifo nosso).

O sentido contrário ao consenso dependentista/estruturalista, ou seja, em uma noção para quem o desenvolvimento da agricultura é função da expansão da industrialização (em consequência, da expansão da divisão social do trabalho) - que ocorre nas cidades é muito presente em Lênin. A manifestação da influência leniniana sobre Rangel é sugestiva na seguinte manifestação:

(...). It is well known that in all capitalist countries the development of towns, factories, industrial settlements, railway stations, ports, etc., stimulates a demand for this type of product, it pushes up their prices, and increases the number of agricultural enterprises raising them for the market. The average "vegetable" farm has less than onethird of the improved acreage of an "ordinary" farm deriving income chiefly from hay and grain: the former is 33.8 acres, and the latter, 111.1. This means that this particular technical level with this particular accumulation of capital in agriculture requires "vegetable" farms of smaller acreage; in other words, if capital invested in agriculture is to yield a not less-than average profit, a vegetable-raising farm should have, technology being what it is, a smaller acreage than a hay-and grain farm.

Outro ponto leniniano, absorvido por Rangel, está na relação - em Lênin - imperialismo/desenvolvimento desigual, como segue (Lenin, 1916 [1984], p. 162):

Por vigoroso que tenha sido, durante os últimos decênios, o nivelamento do mundo, a igualização das condições econômicas e de vida dos diferentes países sob a pressão da grande indústria, da troca e do capital financeiro, a diferença continua a ser, no entanto, respeitável, e entre os seis países indicados encontramos, por um lado, países capitalistas jovens, que progrediram com uma rapidez extraordinária (a América, a Alemanha e o Japão); por outro lado, há países capitalistas velhos que, durante os últimos anos, progrediram muito mais lentamente do que os anteriores (a França e a Inglaterra); em terceiro lugar figura um país, o mais atrasado do ponto de vista 
econômico (a Rússia), no qual o imperialismo capitalista moderno se encontra envolvido, por assim dizer, numa rede particularmente densa de relações pré-capitalistas.

Seguindo esta linha de raciocínio, na obra rangeliana, observa-se o seguinte pressuposto (Rangel, 2005, p. 271):

Com efeito, já Lenin havia observado que o desenvolvimento desigual é uma lei do capitalismo. Contra a noção vulgar de um desenvolvimento fazendo-se com a ordem de uma parada militar, guardando cada unidade as distâncias regulamentares relativamente às que que a precedem ou sucedem, mostrou ele que, na vida real, as posições se trocam, se embaralham, mudam-se constantemente os balanços mundiais de força, passando inoptadamente um retardatário, para uma posição de vanguarda, e vice-versa.

$\mathrm{Na}$ entrelinha, isso significa capacidade de o Brasil tirar proveito dos choques interimperialistas e as respectivas transformações históricas no âmbito da hegemonia no centro do sistema capitalista. É fato objetivo que ao capital industrial inglês interessava nossa independência de Portugal e, consequente, desenvolvimento do capitalismo comercial brasileiro. Da mesma forma aos EUA, o rompimento brasileiro com a Inglaterra - no âmbito da Revolução de 1930 - seria interessante, e diante, à mudança de formas de exportações de capitais que passaram a ser concentrada em implantação de cadeias produtivas, dos EUA à periferia do sistema. Não seria nenhum exagero afirmar a hostilidade norte-americana ao progresso da periferia como um todo e do Brasil em particular, sobretudo a partir de meados da década de $1970^{14}$.

Sobre a leitura de Rangel de $O$ desenvolvimento do capitalismo na Rússia (Lenin, 1899 [1964]) ${ }^{15}$. Cabe destacar a relação entre o suposto

(14) É famosa a frase atribuída a Henry Kissinger sobre as possibilidades abertas pelo desenvolvimentismo brasileiro, “ (...) não Permitiremos um Novo Japão ao Sul do Equador".

(15) Trata-se de um longo livro lançado em 1899, onde cerca de 4000 dados estatísticos servem de base ao argumento do autor. Do ponto de vista do método da Economia Política, esta obra insere-se em um momento onde a matemática não se aplicava de forma arbitrária nos trabalhos econômicos, pois a estudo das múltiplas determinações do processo, partindo da observação/percepção dos fatos já era uma prática recorrente à época onde, independente da própria experiência, observava-se uma questão sair das raias da descrição à explicação. 
leniniano no citado livro com a problemática central da economia brasileira. Na Rússia do final do século XIX o avanço do capitalismo irradiava profundas mudanças em sua estrutura industrial e agrária, tendo como manifestação mais perceptível no desmonte do complexo rural, minando as bases de um sonho de transição ao socialismo partindo do mir rural, como acreditavam os narodniks (populistas). Acreditavam os populistas sobre a impossibilidade de realização da mais-valia por ausência de pequenos produtores e o próprio mercado externo. A resposta de Lênin, baseando-se no desenvolvimento como um processo movido pela cidade, está no fato, para quem a que a diferenciação social (por exemplo, na via americana, onde pequenos produtores se transformam em granjeiros ou em trabalhadores assalariados) era fator central à formação do mercado interno, a especialização da agricultura (divisão social do trabalho) $e$ as respectivas substituições naturais e artesanais de exportações.

Rangel nunca pôs a si a tarefa de explicar as razões do atraso brasileiro e de seu subdesenvolvimento. Colocou-se a tarefa de apontar os caminhos que explicativos de nosso dinamismo, os limites ao nosso desenvolvimento e onde se localizavam as possibilidades ao próximo passo (síntese) numa espiral que converteria o capitalismo industrial em capitalismo de Estado (via formação de um amplo aparelho de intermediação financeira nacional), e daí ao socialismo. Tavares (1977, p. 18), confirma esta postura, conforme segue:

A esta altura, entre os chamados 'economistas heterodoxos', primava ainda, a interpretação estagnacionista, derivada de uma análise da tendência, projetada e entendida como o 'limite' do modelo de expansão anterior. Um dos poucos economistas brasileiros do meu conhecimento que não participava dessa visão era Inácio Rangel, ao qual devo as mais importantes intuições sobre a natureza central da acumulação naquele período de transição - a necessidade de transferir excedentes dos setores atrasados ou poucos dinâmicos para os de maior potencial de expansão.

Voltemos a Lênin, e de forma mais preciso ao uso da categoria de formação social em $O$ desenvolvimento do capitalismo na Rússia. Explicar como o capitalismo se desenvolvia (na Rússia), cercado de feudalismo, 
levou Lênin à elaboração de uma chamada lei objetiva da formação social intrínseca na relação entre atraso $x$ dinamismo. O Brasil do final do final do século XVIII e nos séculos XIX e XX é expressão desta lei objetiva onde o escravismo não impediu o país de inundar o mundo de café e colocar o Brasil em franca concorrência com os EUA ao suprimento de algodão à Inglaterra. $\mathrm{O}$ século $\mathrm{XX}$ foi marcado pelo fato de o Brasil ter sido o país que mais cresceu no período e mesmo o neoliberalismo não impediu - de forma direta - a transformação da região nordeste na maior incubadora de empreendedores individuais do país. Longe de ser uma combinação de atraso x estagnação, de forma brilhante implantou-se no Brasil um moderno Departamento 1 Novo (indústria mecânica pesada) e um sofisticado sistema financeiro.

As desigualdades persistem - fruto de uma via prussiana, industrialização sem reforma agrária. Porém, o processo de industrialização deve ser visto não de forma estática e sim em dinâmica que deverá ser encerrada em outra vaga de crescimento acelerado, altas taxas de investimento e plena tomada do papel histórico pela iniciativa privada nacional e do Estado como regulador do comércio exterior e dos instrumentos cruciais ao processo de acumulação (câmbio, juros, crédito e sistema financeiro). É perceber a contradição gerada pelo processo, porém sem se perder em tal. É concentração na síntese, não na antítese.

\subsection{Ciclos, desequilíbrio e desenvolvimento: Keynes e Schumpeter}

Cabe destaque à influência exercida por Keynes e Schumpeter sobre o pensamento de Ignacio Rangel, algo que ocorre à moda do próprio autor: de forma criativa, original e longe de o afastar do fundamental de sua origem marxista. A aceitação de pressupostos keynesianos e schumpeterianos foi inserida, partindo da constatação marxista da possibilidade de crises sistêmicas, diretamente relacionadas à contradição principal do modo de produção capitalista (produção social x apropriação privada do excedente), presentes na quebra do ciclo do capital, D-M-D'. Neste sentido, segundo Bielshowsky (1996, p. 221), Rangel absorveu Keynes, e combinou com o marxismo: 
(...) pela via da compatibilização com a interpretação subconsumista da teoria econômica de Marx, ou seja, da interpretação assentada sobre a ideia de que, no capitalismo, as forças produtivas estariam amarradas pela insuficiência de demanda que decorre da forma privada de apropriação do resultado do esforço produtivo.

Subconsumo e insuficiência de demanda formam um nexo explicativo tanto à periodicidade cíclica das crises quanto o papel virtuoso do Estado. Na visão de Rangel, tal como em Hirschman (1958), o desenvolvimento é um processo de saltos entre um desequilíbrio e outro (logo, gerador de elos fortes e elos débeis em sua estrutura industrial) e de transferência de recursos de setores superinvestidos para outros onde a possibilidade de expansão é iminente (dialética da capacidade ociosa) ${ }^{16}$. Além da visão nacional muito precocemente embutida em sua atividade política e intelectual, certamente o desenvolvimentismo de Rangel está intimamente relacionada com a leitura de Keynes: se o desenvolvimento econômico é observado como fenômeno, certamente seu aspecto nomenal deve residir na relação que faz Keynes entre Estado, iniciativa privada e a variável independente no investimento ${ }^{17}$.

Mesmo que de forma superficial colocamos em evidência, acima, a intimidade - para Rangel - na relação entre ciclos econômicos, o papel do Estado pelo instrumento do Princípio da Demanda Efetiva e o indutor nela encerrado pelo investimento. $\mathrm{O}$ investimento é parte essencial do processo de reprodução do capita concomitante à importância do progresso técnico ao próprio espiral do processo de acumulação de capital. Ora, a questão que se coloca é como Rangel - partindo do vértice inerente à historicidade

(16) Além do Princípio da Demanda Efetiva, esta questão da dialética da capacidade ociosa deve ser vista como um dos pontos de encontro entre Rangel e Kalecki. Segundo ambos o grau de monopolização das economias capitalistas é fato explicativo à operação do sistema em capacidade ociosa induzida e respectivas anomalias do que tange o sistema de formação de preços. Kalecki não poderia, neste caso, ser assinalado como uma das influências de Rangel. Rangel, certamente, não o conheceu apesar da convergência de sínteses entre os dois; resultado do ponto de partida de ambos no marxismo.

(17) Assim como M. Kalecki, Thorstein Veblen é outro autor cuja convergência com a obra de Rangel pode ser observada. Segundo Mitidieri (2014, p. 286): A descrição de Rangel sobre o modus operandi do setor agrícola se aproxima muito do conceito de Sabotage, desenvolvido pelo economista americano Thorstein Veblen em seu livro The engineers and the price system. Em Veblen, o conceito de Sabotage é muito mais complexo, sendo que a inflação é uma forma de Sabotage. (...). 
germânica de Hegel e Marx, acrescido do binômio imperialismo/desenvolvimento desigual de Lênin - empreende uma síntese de tais categorias com as noções de ciclos de acumulação, investimento e progresso técnico.

O encontro de Rangel com as ondas largas da economia internacional ocorre de seu contato com a obra e o pensamento, e posterior influência, de Joseph Schumpeter. Autor este responsável direto pela sobrevivência intelectual post mortem de Nicolai Kondratiev. Em Schumpeter (1939), baseado em Kondratiev, os limites do processo de acumulação residem justamente na capacidade do sistema como um todo de não somente produzir novíssimas tecnologias, mas principalmente em absorver o progresso técnico - dada a unidade de contrários entre empresas de ponta e outras de caráter marginal -, gerando assim um novo ciclo ascendente na economia, após uma, nas palavras de Rangel, verdadeira metástase tecnológico-econômica ${ }^{18}$.

Outra questão que se coloca diante desta influência intelectual de Rangel é a relação entre os ciclos longos, que são gerados no centro do sistema capitalista, com a lógica reprodutiva do capital no Brasil e suas dualidades mediadas por grandes arranjos de caráter institucional ${ }^{19}$. Resumidamente, é de conhecimento geral que grandes desarranjos nas economias centrais se refletem diretamente sobre não somente o processo periférico de acumulação de capital (dada a importância da variável "comércio exterior" às diferentes periferias), mas redundam em transformações qualitativas, ou não, no âmbito de suas superestruturas. Ao Brasil, de forma coincidente, transformações institucionais demandaram precedência de crises sistêmicas. Neste sentido é fundamental relacionar 1888/1889 com a crise europeia datada no mesmo período, assim como a

(18) A utilização e caracterização desta citação rangeliana foi muito bem analisada em: Tolmasquim (1991).

(19) O Brasil, por seu caráter reflexo das economias centrais não foi ainda capaz de gerar/internalizar os seus próprios ciclos longos. Este longo processo histórico está diretamente determinado pela própria internalização do capital financeiro sob os auspícios de um aparelho nacional de intermediação financeira capaz de fundir-se com nosso capital industrial já existente. A contrarrevolução monetarista, e sua face brasileira, tem sido um imenso retardamento do referido processo. 
Revolução de 1930, e a inauguração do processo de substituição de importações. Isso não significa uma linha reta, determinista entre um processo e outro. Correlações de forças em âmbito mundial e, mesmo, a própria - e atual - natureza das classes dominantes brasileiras são elementos fundamentais à análise no âmbito, e em nome da própria evolução, da Economia Política da nação brasileira.

\section{Considerações finais sobre a importância da obra de Ignacio Rangel}

O desafio de situar o corpo científico construído por Ignacio Rangel ainda está em aberto. E este trabalho não encerra a questão. $\mathrm{O}$ contrário é totalmente verdadeiro, tanto quanto as próprias ideias de Rangel ainda estão na sua infância de desenvolvimento, o que significa que o todo explicativo de sua obra ainda tem um largo caminho a trilhar, diante dos caminhos palmilhados pela história econômica recente do Brasil e, principalmente, do futuro de nossa construção nacional e seu impacto à própria América Latina.

Este trabalho intentou construir a anatomia de um pensador marxista, original e profundamente brasileiro. Desde a herança familiar de independência e combatividade política, passando pelo precoce contato com o contraditório inerente à formação jurídica. Da influência da filosofia clássica grega ao iluminismo que o preparou à Karl Marx, da mesma forma que preparou o próprio Marx, conforme o próprio Rangel ([1963] 2005, p. 552):

Esse culto não era um simples ritual, como o que antes se ensinava nas faculdades. Estava lastreado política e socialmente, e seu conteúdo real era a construção desta extraordinária nação. Seus nomes mais ilustres não estavam em Roma ou Bizâncio, mas na França de 1789. A lei não passava de uma encarnação da razão, e o seu culto era, de fato, um racionalismo. A Enciclopédia preparavame para Karl Marx, como havia preparado o próprio Karl Marx.

Seu espírito independente aliado a uma objetividade histórica incomum o levou a ser ao mesmo tempo um pensador para quem o início de todo processo de criação e compreensão de fenômenos econômicos complexos deveria partir da Economia Clássica até o outro polo: crítico ao próprio marxismo, ou ao menos, crítico da importação de teorias prontas à 
explicação de uma formação social complexa como o Brasil. Seu parti pris não era ideológico redundando numa visão histórica acerca do papel do Estado, da iniciativa privada, do planejamento e do mercado. Daí se ter-se apropriado do marxismo de forma criativa e flexível, não o impedindo de ir à raiz de nossa formação; buscando um sentido ao processo evolutivo do Brasil transformando o materialismo histórico, lastreado por sua universalidade, em algo brasileiro. Bom dizer que a validade teórica do marxismo, assim como a Economia Política, só pode ser perceptível, e potencializado, à medida em que se aproxima do concreto, da essência encerrada na própria formação social. Tornando-se, assim, um poderoso instrumento de compreensão e transformação da realidade. O contrário é o dogma, a profissão de fé, a ideologização, o sectarismo político e o academicismo.

O pressuposto da radicalidade (visão de processo histórico, de formação social) reside no (não) paradoxo da amplitude. A postura rangeliana intrínseca à historicidade das leis da ciência e do duplo caráter evolutivo da ciência econômica o levou a ter uma atitude de respeito e reconhecimento aos pensadores mais antigos, ao essencial de Keynes e Schumpeter e alguns supostos estruturalistas. Praticava não a negação e sim a negação da negação. O que implicava, ao lado de sua amplitude e visão larga de ciência, a tomada de posições desde o levantamento do véu leniniano encerrada na questão agrária, na análise do imperialismo, do desenvolvimento desigual e a lei objetiva da formação social até a denúncia do poder destrutivo do imperialismo e sua face de "inimigo número um da humanidade". Da necessidade de transferência à iniciativa privada nacional de infraestruturas estranguladas concomitante com a necessária estatização/planificação do comércio exterior. E assim, dialética e, sucessivamente.

Enfim, o desafio brasileiro e latino-americano está diante de nós e não deve ser concebido no abstrato (visão ideologizada) e sim pela abstração (visão de processo histórico). Desta forma a continua revisitação à obra de Ignacio Rangel é uma necessidade imposta pela realidade. Se não somente pela realidade, que seja por força de nossa própria formação intelectual, humana e humanística. 


\section{Referências bibliográficas}

BELLUZZO, L. G.: Valor e capitalismo: um ensaio sobre a Economia Política. 1. ed. Campinas: Instituto de Economia da Unicamp, 1998.

BIELSHOWSKY, R. O pensamento econômico brasileiro. O ciclo ideológico do desenvolvimentismo. 3. ed. Rio de Janeiro: Contraponto, 1996.

BRESSER-PEREIRA, L.; REGO, José M. Um mestre da economia brasileira: Ignacio Rangel. Revista de Economia Política, São Paulo, v. 13, n. 2 (50), abr./jun. 1993.

CASTRO, M. H.; BIELSHOWSKY, R.; BENJAMIN, C. Notas sobre a atualidade do pensamento de Ignacio Rangel. Revista de Economia Política, São Paulo, v. 34, n, 4 (137), out./dez. 2014.

DIAS PEREIRA, J. M. O centenário de Ignacio Rangel. Revista de Economia Política, v. 34, n. 4 (137), out./dez. 2014.

ENGELS, F. AntiDüring. 3. ed. São Paulo: Paz e Terra, 1990.

HIRSCHMAN. A. The strategy of economic development. New Haven: Yale University Press, 1958.

KONDRATIEV, Nicolai. Los ciclos largos de la coyuntura economica. México D.F: UNAM, 1992.

KOROTAYEV, Andrey; TSIREL, Sergey V. A spectral analysis of world GDP dynamics: Kondratieff waves, Kuznets swings, Juglar and Kitchin cycles in global economic development, and the 2008-2009 economic crisis. Structure and Dynamics, Irvine, CA, v. 4, n. 1, 2010.

LEITE, P. T. Convergências entre Ignacio Rangel e Delfim Netto: uma análise com base em Lênin. In: HOLANDA, F. M.; ALMADA, J.; AFFONSO DE PAULA, R. Z. (Org.). Ignacio Rangel, decifrador do Brasil. São Luis: EDUFMA, 2014. p. 162-201.

LENIN, V. Imperialismo, fase superior do capitalismo. In: LENIN, V. Obras escolhidas. Lisboa: Avante!, [1916] 1984. v. 2. 
LENIN, V. The development of capitalism in Russia. In: LENIN, V. Collected works. $4^{\text {th }}$ ed. English edition. Moscow: Progress Publishers, 1899 [1964].

LENIN, V. New data on the laws governing the development of capitalism in agriculture. Part one: Capitalism and agriculture in the United States of America. In: LENIN, V. Collected works. Moscow: Progress Publishers, [1915] 1917. v. 22. p. 13-102.

LENIN, V. On the so called market question. In: LENIN, V. Collected works. $1^{\text {th }}$ English edition. Moscow: Progress Publishers, [1893] 1963). v. 1, p. $75-128$.

LENIN, V. New economic developments in peasant life. In: LENIN V. Collected works. $4^{\text {th }}$ English edition. Moscow: Progress Publishers, [1893] 1972. v. 1, p. 11-74.

MAMIGONIAN, A. Introdução ao pensamento de Ignacio Rangel. GEOSUL, Florianópolis, v. 2, n. 3, p. 63-71, 1987.

MAMIGONIAN, A. Notas sobre as raízes e originalidade do pensamento de Ignacio Rangel. In: MAMIGONIAN, A. (Org.). O pensamento de Ignacio Rangel. Florianópolis: Fundação Banco do Brasil - CNPq - PPGGUFSC, 1997. p. 133-140.

MAMIGONIAN, A. O retorno do profeta desarmado. Carta Capital, n. 352, p. 56-62, 2005.

MAMIGONIAN, A. A geografia e a formação social como teoria e como método". In: SOUZA, M. A. A. (Org.). O mundo do cidadão, o cidadão do mundo. São Paulo: Hucitec, 1996.

MAMIGONIAN, A. Ignacio Rangel e seus interlocutores. In: HOLANDA, F. M.; ALMADA, J.; AFFONSO DE PAULA, R. Z. (Org.). Ignacio Rangel, decifrador do Brasil. São Luís: EDUFMA, 2014. p. 75-82.

MARTINS, Carlos E. A teoria da conjuntura e a crise contemporânea. Polis - Revista Latinoamericana, Santiago de Chile, n. 24, 2009.

MERCADANTE, P. Ignacio Rangel e a substância de nossa realidade. In: MAMIGONIAN, A. (Org.). $O$ pensamento de Ignacio Rangel. 
Florianópolis: Fundação Banco do Brasil - CNPq - PPGG-UFSC, 1997. p. $40-48$.

MORENO, O.; MODENEZI, A. A curva de Rangel: origem, desenvolvimento e a formalização de Bresser-Pereira e Nakano. Revista de Economia Política, v. 34, n. 4 (137), out./dez. 2014.

PEDRÃO, F. A dialética da rebeldia desde Rangel até hoje. In: HOLANDA, F. M.; ALMADA, J.; AFFONSO DE PAULA, R. Z. (Org.). Ignacio Rangel, decifrador do Brasil. São Luis: EDUFMA, 2014. p. 83-99.

PREBISCH, R. The economic development of Latin America and its principal problems. Santiago: United Nations Publication, Economic Comission for Latin America, 1950.

PALHANO, R.; CORREAA, R.; COSTA, M.; BRAGA, P. Um fio de prosa autobiográfica com Ignácio Rangel. São Luis: IPES/UFMA/SIOGE, 1991.

RANGEL, I. Fogo, blindagem e conjuntura. GEOSUL, Florianópolis, v. 5, n. 10, p. 7-19, 1990.

RANGEL, I. Ciclo, tecnologia e crescimento. In: RANGEL, I. Obras reunidas. Rio de Janeiro: Contraponto, [1981] 2005. v. 2, p. 255-408.

RANGEL, I. Desenvolvimento e projeto. In: RANGEL, I. Obras reunidas. Rio de Janeiro: Contraponto, [1956] 2005. v. 1, p. 203-284.

RANGEL, I. Dualidade básica da economia brasileira. In: RANGEL, I. Obras reunidas. Rio de Janeiro: Contraponto, [1957] 2005. v. 1, p. 285353.

RANGEL, I. Estrutura agrária, sociedade e Estado. In: RANGEL, I. Obras reunidas. Rio de Janeiro: Contraponto, [1978] 2005. v. 2, p. 87-95.

RANGEL, I. A história da dualidade brasileira. In: RANGEL, I. Obras reunidas. Rio de Janeiro: Contraponto, [1981] 2005. v. 2, p. 655-686.

RANGEL, I. A inflação brasileira. In: RANGEL, I. Obras reunidas. Rio de Janeiro: Contraponto, [1963] 2005. v. 1, p. 551-679.

ROBINSON, J. An essay on Marxian economics. London: Papermac160, 1942. p. xxii. 
ROSTOV. W. W. Kondratieff, Schumpeter, and Kuznets: trend periods revisited. The Journal of Economic History, Cambridge, England, v. 35, n. 4, Dec. 1975. Disponível em: http://www.jstor.org/stable/2119182. Acesso em; 10 jan. 2015.

SALOMON, S. Phases on economic growth, 1850-1973: Kondratieff Waves and Kusnetz Swings. $1^{\text {st }}$. ed. Cambridge: Cambridge University Press, 1987.

SANTOS, M. Sociedade e espaço: a formação social como teoria e como método. In: SANTOS, M. Espaço e Sociedade. $1^{\text {st }}$. ed. Petrópolis: Vozes, 1982.

SERENI, E. La categoria de formación económico-social. Cuadernos de Pasado e Presente, Córdoba, n. 39, 1976.

SCHUMPETER, J. Business cycles: a theoretical, historical, and statistical analysis of the capitalist process. New York: McGraw-Hill Book Company, 1939.

TAVARES. M. C. Da substituição de importações ao capitalismo financeiro. 6. ed. Rio de Janeiro: Zahar, 1977.

TOLMASQUIM, M. T. O Brasil e o ciclo de Kondratieff e Juglar na obra de Ignacio Rangel. Revista de Economia Política, São Paulo, v. 11, n. 4 (44), out./dez. 1991. 